\title{
$\mathrm{PH} 105_{\text {actuaidad }}$
}

\section{El sistema de clasificación funcional de documentos de la Junta de Andalucía presenta su versión 2.0}

Transcurrido algún tiempo desde la publicación, en octubre de 2018, de la versión 1.0 del Cuadro de clasificación funcional de documentos de la Junta de Andalucía, en junio de 2021 se publicaba una versión 2.0. Esta actualización, que implica una profunda revisión conceptual, es fruto de las aportaciones, sugerencias y observaciones de profesionales de la Administración andaluza, tanto del ámbito de los archivos como de fuera del mismo, y del conocimiento de otras experiencias de clasificación funcional. El horizonte para el diseño de esta herramienta, coordinado por al Archivo General de Andalucía, ha sido estar al servicio de la Administración, así como de la ciudadanía, y que no sea solo un instrumento técnico específico reservado al personal de archivos.

Mateo A. Páez García | Director del Archivo General de Andalucía

URL de la contribución <http://www.iaph.es/revistaph/index.php/revistaph/article/view/5065>

Todos los documentos producidos por las administraciones públicas, sus entidades instrumentales, incluso por personas privadas en el desarrollo de funciones públicas atribuidas, son patrimonio documental por origen, y no por antigüedad. Eso implica una cuestión que puede resultar paradójica en esta publicación dedicada al patrimonio "histórico": los documentos electrónicos de las administraciones públicas son también patrimonio documental, y están amparados por todas las medidas de protección que la legislación vigente en materia patrimonial y de archivos y documentos contemplan.

Por ello hay que comprender que todas las operaciones que atañen a la gestión documental son esenciales no solo para la protección de este patrimonio, sino (lo que es más importante) para su disponibilidad a todas las personas usuarias presentes y futuras: Administración, personas interesadas o involucradas en procedimientos administrativos, investigadores o meros curiosos. La clasificación de documentos es una de esas operaciones esenciales, y la administración electrónica pone de relieve más que nunca su papel fundamental.

El desarrollo normativo en torno al documento electrónico como un componente más de la e-administración ha conseguido poner en claro al menos dos cuestiones fundamentales que atañen a la clasificación: en primer lugar, el metadato de clasificación es un requisito de incorporación obligatoria en el expediente electrónico. En segundo lugar, esa clasificación ha de ser funcional.

La obligatoriedad de aplicar una clasificación funcional a los documentos electrónicos, por lo tanto, ha puesto en valor la propuesta de clasificación funcional para los documentos de la Junta de Andalucía (Páez García 2002), que en el año 2004 publicábamos en esta misma revista (Páez García 2004), y que ha servido de base para un largo trabajo desarrollado durante muchos años y por un amplio equipo de personas, coordinado por el Archivo General de Andalucía, a quien la Política de gestión de documento electrónico de la Junta de Andalucía, aprobada por acuerdo del Consejo de Gobierno de 1 de agosto de 2017, le encomienda el mantenimiento del cuadro de clasificación. En junio de 2021 salió a la luz la versión 2.0 de este elaborado trabajo, que presenta importantes novedades (Archivo General de Andalucía 2021).

El principal rasgo diferenciador de esta propuesta de clasificación funcional con respecto a otras es la interpretación del adjetivo "funcional", entendido generalmente en un sentido de ámbito competencial por la mayoría de los sistemas de clasificación desarrollados para administraciones públicas. La clave es entender el funcionamiento de las administraciones públicas, que podemos sinteti- 


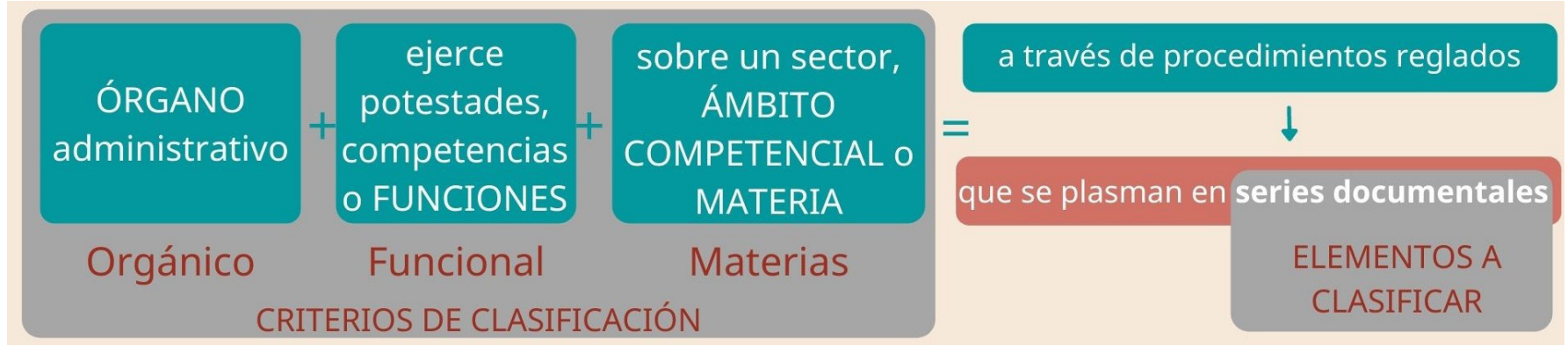

Esquema de la actividad administrativa y su plasmación documental

zar así (ver gráfico de esta página): los órganos administrativos ejercen potestades o competencias sobre una materia o ámbito competencial concreto, atribuido por una norma legal, generalmente a través de procedimientos reglados o trámites administrativos, que en su mayor parte se plasman en documentos.

Como vemos en el gráfico, las tres partes que intervienen en la acción administrativa (órganos, funciones y materias) han sido utilizadas tradicionalmente como criterios de clasificación. Las dificultades para entender aquello que es funcional se desvanecen cuando lo definimos negativamente, es decir, aquello que no es ni orgánico ni perteneciente a la materia o ámbito competencial. Por otro lado hay que tener en cuenta que, aunque lo que vamos a clasificar son documentos, una estructura funcional de clasificación no atiende a los documentos, sino a las actividades de la Administración.

Por lo tanto, todo se reduce a saber, en definitiva, si es posible representar y sintetizar en una estructura lógica y jerárquica de niveles (eso es clasificar) toda la actividad de la Administración de la Junta de Andalucía, independientemente tanto de los órganos que actúan como de las materias o ámbitos cuya competencia corresponde a dichos órganos. Desde el derecho administrativo y desde la ciencia administrativa se da una respuesta afirmativa que resumimos a continuación (ver gráfico superior página siguiente). De un modo muy general, las actividades de una Administración se pueden sintetizar en tres grandes funciones:

1. Una función prestacional o de servicio público, que facilita servicios (como la sanidad o la educación) o entrega bienes (como viviendas sociales) en cumplimiento de unos derechos previamente reconocidos a la ciudadanía.

2. Una función de garantía (tradicionalmente denominada de "policía") que implica todas las técnicas de intervención administrativa en el ámbito privado, que reglamentan la convivencia social para que las actividades de los particulares no entren en conflicto entre sí ni con el interés general.

3. Una función de estímulo, fomento o incentivación de la actividad de los particulares y de la iniciativa privada en aras de su orientación al interés general.

A estas tres funciones tradicionales hay que añadir una cuarta que cada vez se configura con más fuerza y que supone un auténtico cambio de paradigma de la relación entre ciudadanía y Administración: aquella no es ya simplemente la que soporta de manera pasiva como "administrada", o de manera activa como "interesada" la acción administrativa, sino que se convierte en protagonista en el diseño, ejecución y supervisión de las políticas públicas, y se han de desarrollar mecanismos adecuados de participación ciudadana y de protección de sus derechos.

No acaba aquí toda la actuación de una Administración. Las funciones a las que nos hemos referido son finalistas, pero no se pueden llevar a cabo sin:

$>$ Una actividad medial, que contempla toda la gestión de los medios personales, materiales, económicos y financieros $y$, por supuesto, informativos y documentales, utilizados para alcanzar los fines anteriores. 
FUNCIONES DE LA ADMINISTRACIÓN PÚBLICA

\section{DIRECCIÓN}

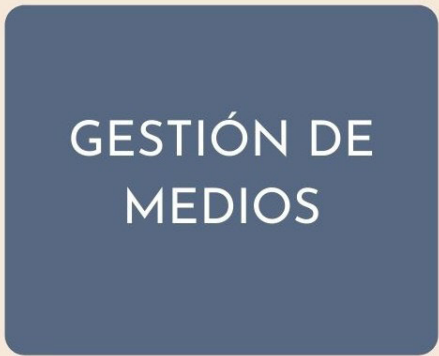

PRESTACIÓN

GARANTÍA

FUNCIONES DEL SISTEMA DE CLASIFICACIÓN FUNCIONAL DE DOCUMENTOS DE LA JUNTA DE ANDALUCÍA

\section{GOBIERNO Y DIRECCIÓN}

2 GESTIÓN DE RECURSOS HUMANOS

3 GESTIÓN DE RECURSOS PATRIMONIALES

4 GESTIÓN ECONÓMICA, FINANCIERA Y CONTRATACIÓN

5 COMUNICACIÓN, INFORMACIÓN Y GESTIÓN DE LOS DOCUMENTOS

6 ASISTENCIA Y ASESORAMIENTO

\section{PRESTACIÓN DE SERVICIOS PÚBLICOS}

7 ORDENACIÓN Y CONTROL

11 SEGUIMIENTO Y EVALUACIÓN

8 FOMENTO

\section{PARTICIPACIÓN 10 PARTICIPACIÓN CIUDADANA Y PROTECCIÓN DE DERECHOS}

Funciones del Sistema de Clasificación Funcional de Documentos de la Junta de Andalucía

\section{CLASES O CATEGORÍAS} DE CLASIFICACIÓN

Nivel 1

Nivel 2

Nivel 3

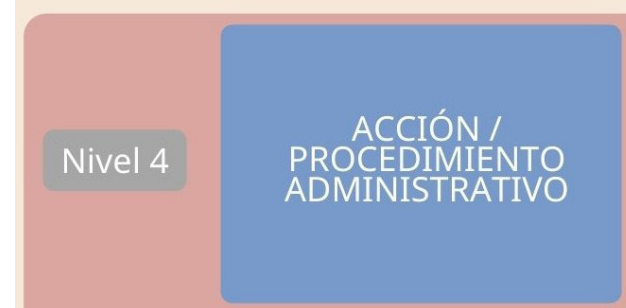

FUNCIÓN

DIVISIÓN DE FUNCIÓN

ACTIVIDAD
Niveles jerárquicos del Sistema de Clasificación Funcional de Documentos de la Junta de Andalucía
Responsabilidad u objetivo principal realizado por la Administración autonómica en el ejercicio de una competencia atribuida, que está integrada por un conjunto de actividades o procesos.

Cualquier agrupación de actividades o procesos en que puede dividirse una función.

Conjunto de acciones o tareas realizadas por uno o varios agentes (órganos de la Administración autonómica) para cumplir una función determinada o parte de ella.

\section{Conjunto ordenado de trámites y} actuaciones formalmente realizadas, según el cauce legalmente previsto, para dictar un acto administrativo o expresar la voluntad de la Administración. que se plasman en series documentales

\section{ELEMENTOS A \\ CLASIFICAR}


> Una función de gobierno y dirección que está por encima de todas las anteriores y que establece los fines y objetivos a alcanzar.

Sobre este esquema general se ha construido una jerarquía de tres niveles (función, división de función y actividad, de mayor a menor), dentro de la cual se encajan las series documentales como testimonios de los procedimientos administrativos, ese "conjunto ordenado de trámites y actuaciones formalmente realizadas, según el cauce legalmente previsto, para dictar un acto administrativo o expresar la voluntad de la Administración", como se define en la Ley 39/2015. Esta relación entre la acción administrativa y las evidencias documentales en las que se plasma es la que nos permite engarzar el esquema funcional con las series documentales, que son los elementos a clasificar dentro de ese esquema (ver gráfico inferior página anterior).

Toda la actividad administrativa queda resumida de este modo en diez grandes funciones. Otro aspecto interesante de esta versión 2.0 es la comprensión de que el cuadro de clasificación no es más que una herramienta o elemento dentro de un amplio sistema de clasificación, que incluye el marco normativo, un modelo conceptual, el cuadro de clasificación fuente, los cuadros de clasificación elaborados para cada organismo y entidad, el repertorio de series documentales, así como los catálogos para las entidades de función. Todo ello bajo el sostén de @rchivA como herramienta corporativa para el mantenimiento de todo el sistema, dentro de la gestión documental de la Junta de Andalucía.

\section{BIBLIOGRAFÍA}

- Archivo General de Andalucía (2021) Clasificación funcional de documentos de la Junta de Andalucía. Sevilla, Consejería de Cultura y Patrimonio Histórico. Disponible en: http://www. juntadeandalucia.es/cultura/archivos_html//sites/default/ contenidos/archivos/aga/difusion/DocumentosTecnicos/CCF_ V2.0_h_MAYO_2.pdf [Consulta: 12/11/2021]

- Páez García, M.A. (2002) Cuadro de clasificación funcional para fondos de Archivos del Subsistema Autonómico Andaluz. El Fondo de la Consejería de Agricultura y Pesca. Sevilla: Consejería de Agricultura y Pesca
- Páez García, M.A. (2004) El cuadro de clasificación integrado: normalización de la clasificación archivística. Revista PH, n. ${ }^{\circ}$ 47, pp. 84-95. Disponible en: http://www.iaph. es/revistaph/index.php/revistaph/article/view/1691 [Consulta: $12 / 11 / 2021]$ 